\title{
Memória em movimento: a experiência videográfica do LABHOI/UFF*
}

\author{
Ana Maria Mauad e Paulo Knauss**
}

No dia 17 de dezembro de 1961, na cidade de Niterói, o Gran Circus Norte-Americano, faltando pouco para terminar sua sessão vespertina, ardeu em chamas, deixando um rastro de mortos, feridos e mutilados. A notícia correu todo o país e mobilizou ajuda vinda de diferentes partes do Brasil e do exterior, inscrevendo-se na memória coletiva de diferentes maneiras: pela dor da perda; pela comoção social; pelo mito do incêndio; pelo trauma coletivo; pela fundação de um novo cemitério; pelo desenvolvimento de técnicas de cirurgia plástica. sob a liderança de Ivo Pitanguy no atendimento às vitimas; pelo aparecimento do profeta Gentileza (personagem urbano da região metropolitana do Rio de Janeiro que pregava pelas ruas das cidades) - enfim, por uma série de imagens que se inscreveram pela memória na história da cidade de Niterói, na região metropolitana do Rio de Janeiro.

Quarenta anos depois do incêndio, a equipe do Laboratório de História Oral e Imagem da UFF trabalhou a memória do acontecimento por meio de uma série de entrevistas feitas com sobreviventes, parentes e amigos de vítimas, médicos e outros sujeitos sociais envolvidos na trama dos acontecimentos. O planejamento da pesquisa sobre o incêndio do

* Uma versão anterior deste texto foi apresentada no VII Encontro Nacional de História Oral "História e Tradição Oral", promovido pela Associação Brasileira de História Oral, realizado em Goiânia, 18 a 21 de maio de 2004.

** Pesquisadores do Laboratório de História Oral e Imagem (Departamento de História - Universidade Federal Fluminense). 
Gran Circus Norte-Americano foi marcado pelo compromisso de integração ensino-pesquisa que caracteriza o trabalho do LABHOI. O projeto foi composto a partir da organização de uma disciplina de graduação, ministrada ao longo do segundo semestre de 2001 no curso de graduação em História da UFF, em que alunos, sob orientação de professores, realizaram entrevistas com pessoas envolvidas no desenrolar dos fatos a serem estudados. Além disso, o trabalho envolveu o trabalho sistemático de monitores e bolsistas de iniciação científica em arquivos e bibliotecas, arrolando imagens e notícias veiculadas na imprensa da época.

O resultado deste trabalho foi a reunião de um conjunto de fontes de memória, principalmente orais e visuais. Tais fontes foram entrelaçadas na composição de uma narrativa videográfica que teve como objetivo original temporalizar as imagens através da memória atualizada pelo relato oral, produzindo-se um vídeo de 21 minutos. O significado processado pelo tempo vivido da memória foi reelaborado, valorizando a dimensão da intertextualidade, relacionando palavras e imagens, resultando numa narrativa polifônica onde os tempos históricos se cruzam.

Essa experiência permite, assim, apresentar toda a dinâmica de feitura do vídeo, o trabalho em colaboração com alunos de graduação na elaboração de um produto para ser retornado aos nossos entrevistados da pesquisa, e no qual os próprios alunos reconhecem seu trabalho. Tudo com o objetivo de refletir sobre a relação entre vídeo e história oral, delimitando o campo historiográfico no qual se inscrevia a proposta de ensino e pesquisa desenvolvida.

\section{Definindo o campo historiográfico}

Em 1961, o cinema foi tratado na conhecida coletânea francesa sobre a metodologia do conhecimento histórico dirigida por Charles Samaran (1961). ${ }^{1}$ Nessa obra consagrada do mundo da pesquisa histórica, reprovava-se o caráter enganoso das imagens para restituir a veracidade do real. Essa posição contrasta com o famoso artigo de Marc Ferro sobre o filme

1 Confira-se, especialmente, a parte dedicada aos testemunhos fotográficos e cinematográficos, de autoria de Georges Sadoul. 
como contra-análise da sociedade, incluído, em 1974, na obra coletiva fundadora da Nova História francesa e que marcou a renovação da historiografia contemporânea (Ferro, 1982). Então, o documento fílmico surgiu como um indício através do qual seria possível chegar aos conflitos e disputas no interior de uma dada sociedade. Ao definir o cinema como um documento privilegiado, facilitando a contra-análise da sociedade, os filmes-documentos são reveladores, porque permitem fazer surgir o inesperado, o involuntário - mais do que os documentos escritos. Dessa forma, os filmes podem revelar alguns dos silêncios da história oficial, permitindo alcançar, além da realidade representada, uma zona da historia escondida, fugidia, invisível. Além disso, admite-se a importância do cinema como agente da história, com uma particular eficácia política e social.

Desde então, outros historiadores vêm integrando o cinema entre suas fontes, porém, mesmo reconhecendo no cinema uma função social importante, nem sempre concedem à imagem o mesmo papel crítico de outros documentos. Henry Rousso, em seu livro sobre o governo na França de Vichy durante a Segunda Guerra Mundial, analisa a evolução dos filmes sobre a ocupação francesa como vetor daquilo que ele caracteriza e denomina como a "síndrome de Vichy". Rousso vê, ao lado das comemorações e dos livros de história, o cinema como uma expressão da memória nacional e sublinha, ao mesmo tempo, a dificuldade em definir os limites entre a representação cinematográfica do passado e a construção de uma memória coletiva sobre o mesmo passado.

Sempre existiu uma história do cinema escrita por cinéfilos, sacralizadora de mitos e gênios, e elaborada com um método de análise que valoriza a particularidade da linguagem, com fontes baseadas, em geral, na memória de quem as escrevia, ou de alguns poucos que vivenciaram algumas situações. Esse tratamento põe em questão os níveis de autonomia da história do cinema em relação à própria história social. Os historiadores profissionais desconfiam da história do cinema memorialista, já que lhes parece construída sob o império da subjetividade ou, no melhor dos casos, construída segundo os princípios de um empirismo erudito, mas sem outra preocupação além da conservação de pistas que parecem destinadas a destacar a particularidade do cinema, sem um tratamento problemático de sua inserção social. A ausência de uma abordagem crítica e conduzida metodicamente para a história do cinema anda junto com a dificuldade de enfrentar o desafio de relacionar história e cinema. 
Por outro lado, de que falamos quando tratamos do cinema desde uma perspectiva histórica? De filmes, sem dúvida, mas, a não ser que nos contentemos com uma descrição filmográfica (do tipo arqueológico), é preciso considerar a possibilidade de falar também por meio deles ou, a propósito deles, de muitas outras coisas que parecem dar sentido, espessura e valor à imagem projetada na tela. Quer dizer, no lugar de nos contentarmos em analisar os textos fílmicos do ponto de vista histórico, situando-os meramente em relação ao seu contexto, encontramo-nos propondo um programa globalizante que contém múltiplas dimensões, não só culturais mas também políticas, econômicas e sociais (Rousso, 1990). Tratase, assim, de investigar as formas visuais do cinema; os regimes de realização e autoria; os públicos e a recepção do cinema; as instituições promotoras da produção e do controle de filmes; as representações sociais e a repercussão política e ideológica das imagens em movimento. Importa enfatizar que a relação entre história e cinema não é necessariamente linear e que tanto a criação como a sociedade vivem de suas tensões.

\section{Coordenadas para uma pesquisa (a propósito de Marc Ferro em Cinema e História)}

A ação do cinema sobre a sociedade se exerce por meio de um certo número de modos de ação que tornam o filme eficaz, operatório. Esta capacidade está associada à sociedade que produz e recebe o filme. Além das características não cinematográficas (condições de produção, formas de comercialização, seleção de gêneros, referência a significados culturais, etc), o cinema dispõe de certo número de modos de expressão, que não se caracterizam como mera transcrição da escrita literária, mas que têm, sim, sua especificidade. Seria ilusório imaginar que a prática dessa linguagem é inocente. Por exemplo: um procedimento aparentemente utilizado para exprimir duração, ou ainda uma outra figura de estilo transcrevendo um deslocamento no espaço, etc., pode revelar zonas ideológicas e sociais, de que o cineasta não tinha necessariamente consciência, ou que acreditava ter rejeitado. A sociedade se trai pela censura, em todas as suas formas, inclusive a autocensura.

Nesse sentido, todo filme tem uma história que é a História, com sua rede de relações pessoais, estatuto social de objetos e homens, a partir 
da qual privilégios e encargos, hierarquias e honras são estabelecidos, assim como os lucros da glória e do dinheiro são regulamentados com precisão ritualística. Além disso, Eisenstein já havia observado a propósito da alegoria do açougue em $A$ Greve, que toda a sociedade recebe as imagens em função da sua própria cultura. Em uma passagem desse famoso filme, a platéia rural não se comoveu com a cena da matança de animais, enquanto na platéia urbana a mesma cena causou um grande impacto. Afinal de contas, na experiência da vida no campo, principalmente na Rússia do início do século XX, o abate de animais era uma atividade trivial. O olhar deve ser assim considerado parte da cultura que demarca uma sociedade e a experiência de seu tempo.

Ao lado da leitura histórica do filme, é possível propor uma leitura cinematográfica do passado, colocando outro eixo a ser seguido pelos que interrogam a relação entre cinema e história. A leitura cinematográfica do passado coloca o historiador diante do problema de sua própria escrita da história. A experiência de diversos cineastas contemporâneos, tanto no campo da ficção quanto da não-ficção, demonstra que, graças à memória popular e à tradição oral, é possível desenvolver uma abordagem do passado a partir da criação filmográfica. Esta última diretriz de Marc Ferro orienta-nos no questionamento das possibilidades do uso da escrita fílmica no campo dos estudos históricos. Nesse sentido, é fundamental refletir sobre a questão do documentário de história como produto historiográfico.

\section{Escrevendo história por meio de imagens em movimento}

Escrever a história por meio do recurso da criação videográfica define-se como parte do universo dos filmes documentários, caracterizando nesse campo um recorte temático. Estudiosos e críticos do documentário já enfatizaram as implicações ideológicas existentes na representação da realidade por meio desta modalidade fílmica. A objetividade realista do documentário, por exemplo, pode facilmente escamotear o fato de que o filme está baseado numa certa visão de mundo, demarcando o caráter subjetivo do conhecimento. Entre outros fatores, tal visão é traduzida por: concepções estabelecidas pelo diretor; perspectivas a partir da qual os acontecimentos foram testemunhados; e princípios de edição do material visual. Em outras palavras, o documentário, mesmo lidando com 
fatos efetivos da realidade, não pode jamais ser completamente objetivo, pois resulta, em maior ou menor grau, da intervenção por parte do documentarista. A questão da intervenção, portanto, é o aspecto central da avaliação dos diferentes tipos de documentário, a ponto de ser o elemento que define os modos de documentar.

Se pensarmos no documentário como um gênero, tão substantivo como a ficção ou o jornalismo, somos tentados a ver os modos de documentar como partes desse gênero. Entretanto, ao contrário dos subgêneros, esses modos diferem entre si a partir da forma de representar o objeto documentado, e só depois disso distinguem-se a partir da natureza do tema proposto. Os modos documentais são distintos, na medida em que cada um dos seus formatos acaba por atender a uma determinada necessidade temática. Podemos indicar os seguintes pontos de apoio para uma primeira tipologia: $1^{\circ}$ tipo: expositivo (o narrador fala como autoridade); $2^{\circ}$ tipo: observador (ou cinema direto); $3^{\circ}$ tipo: interativo (intervenção direta dos participantes, na frente e por trás das câmeras); $4^{\circ}$ tipo: modo reflexivo (envolve a elaboração de uma narrativa através da qual o mundo é representado de uma forma bem mais complexa, incluindo a discussão sobre memória, através de uma ruptura da perspectiva linear do tempo - envolve inclusive uma percepção autoral do documentário); $5^{\circ}$ tipo: espetacularização da realidade (une entretenimento e jornalismo, geralmente associado a "fatos monstruosos") (Nora, 1976). Vale ressaltar que como qualquer tipologia, a definição dos formatos segue uma orientação geral, podendo, por exemplo, um documentário do tipo reflexivo utilizar-se estratégias do interativo.

Estas indicações permitem perceber que a relação entre história e documentário fílmico caracteriza um campo diversificado, pois o recorte temático da história não basta para uma definição particular do documentário histórico. Além disso, apontam para uma discussão das definições do campo historiográfico, bem como estratégias de composição do argumento, modalidades de fontes a serem utilizadas, pressupostos epistemológicos do conhecimento produzido, a própria idéia de autoria e de verdade histórica. Nessa discussão, portanto, são definidos problemas tanto de ordem técnica quanto de ordem ética.

Do ponto de vista técnico, há de se apontar que existem diferenças entre o recurso videográfico e o recurso cinematográfico na produção de um texto historiográfico de natureza visual. A película tem muito mais 
definição visual do que o vídeo, por exemplo. Por sua vez, enquanto no cinema uma dada imagem pode sustentar toda uma idéia, o som no vídeo, às vezes, é muito mais importante do que a imagem em si - um vínculo com a Historia Oral que pode ser valorizado. $\mathrm{O}$ vídeo permite ao pesquisador realizar várias entrevistas, com quantas horas quiser, devido às facilidades do manuseio do equipamento e de sua manutenção, o que com a película seria muito difícil devido a problemas estruturais como o tamanho do rolo do negativo e os custos de filmagem. No entanto, um não elimina a possibilidade do outro, pois se pode muito bem utilizar o vídeo primariamente e depois passar para a película o que já foi gravado (Mraz, 1999).

Além disso, a composição de um documentário histórico baseia-se no exercício de combinação de registros de natureza diversa - que se completam ainda pelos registros narrativos não documentais, como narrador, direção de arte, intertítulos, sonoplastia e movimentos de câmera complementares, estabelecidos pelas opções da abordagem fixada no roteiro. Desse modo, a criação do vídeo histórico recorre com freqüência à combinação de imagens fixas com imagens em movimento para composição dos registros de caráter documental. Nesse caso, utiliza-se a fotografia como parte do corpo de imagens do filme. O elemento que facilita a utilização das fotografias é o fato de que estas são mais fartas do que gravações em movimento no tratamento de fatos de um passado mais remoto, além de serem reproduzidas com um custo mais baixo do que as películas.

Nesse mesmo sentido, ocorre a combinação de imagens e lembranças registradas em entrevistas - o que também aparece com freqüência como recurso documental. Para alguns documentaristas, as entrevistas filmadas podem levar a uma certa distorção, conseqüência do constrangimento imposto pela relação interpessoal entre entrevistador e entrevistado que se cria pelo ato de filmar, pelos equipamentos (principalmente a luz e microfone) e técnicos. Para outros, todo aparato e pessoal de filmagem pode levar os entrevistados a uma postura mais rigorosa, fazendo com que sejam mais claros e honestos em seu depoimento. As opções arroladas apontam para caracterizar o documentário histórico como uma modalidade polifônica, pois tem como base a diversidade dos registros documentais, de natureza tipológica e de conteúdos variados, valorizando a construção intertextual e interdiscursiva dos fatos do passado. 
Outro aspecto a se considerar é a construção da narrativa histórica. Esta traduz o fio da interpretação do passado proposto pela historiografia de vídeo ou filme. A narrativa pode ser explicitada por um narrador presentificado na imagem, ou não. Importa frisar que a presença da imagem ou voz de um narrador não é a única forma de se elaborar o fio narrativo do documentário. É a seqüência de imagens que fixa a narrativa que se impõe no curso do filme, combinada com registros visuais e sonoros diversos. Nesse caso, os eventuais intertítulos ou recursos de sonoplastia conduzem o olhar. Do mesmo modo, o movimento da câmara sobre imagens fixas traduz a interpretação a ser construída pelo percurso do olhar. A recorrência às mesmas imagens, ou sons, ou depoimentos, funcionam como leitmotiv da leitura proposta com base nos documentos de época. $\mathrm{O}$ narrador existe mesmo onde não há a figura explícita de uma voz que narra e fixa a leitura proposta dos documentos, e se afirma num roteiro que conduz os sentidos a partir do olhar e dirige interpretação que se impõe diante do expectador, propondo leituras fechadas ou abertas do objeto documentado pela elaboração videográfica.

Assim, uma vez que os historiadores selecionam seu material de acordo com o que confirma o seu argumento, as entrevistas devem ser entendidas como elementos da estrutura narrativa do vídeo, assim como as fotografias e os sons previamente selecionados. Sua posição no tempo do vídeo, diante da lente da câmara, e a relação entre os diversos registros documentais, revelam a função narrativa de cada um deles, o que caracteriza o documentário propriamente dito, que propõe uma leitura interpretativa que constrói a mediação entre o objeto e o sujeito do olhar. Evidentemente, a investigação de imagens garante a maior evidência do tema documentado no filme, operando sobre o sentido da visão, dando mais corpo aos fatos e, ao mesmo tempo, evitando uma construção genérica ou estereotipada. O uso das fotografias nos vídeos produzidos fornece um reconhecimento maior da época e do contexto analisado, dando consistência visual ao tema, além do que, faz com que o público passe a conhecer acervos que não seriam facilmente vistos, provocando a reflexão sobre a interpretação que está sendo oferecido.

Quanto ao uso da voz dos entrevistados, sempre há problemas de produção, pois é preciso tomar vários cuidados em relação ao tom, à velocidade, à dicção, se há erros ou vícios de linguagem, o que nem sempre se pode controlar diretamente. O uso da voz dos entrevistados consiste 
em dar um caráter mais verossímil aos fatos relatados, já que o público pode perceber pela imagem ou apenas pela voz quem está por trás das informações estáticas, reconhecendo sexo, idade, raça e classe daqueles que vivenciaram a situação documentada. Através das entrevistas podemos ter acesso igualmente a informações que estão fora das fontes escritas. Em especial revelam uma outra ordem de percepção dos fatos, pois ao vermos as reações corporais, a entonação e o caráter da voz, quando os entrevistados falam sobre determinado assunto, reconhecemos a base subjetiva e emocional da experiência dos sujeitos sociais da história.

Acima de tudo, interessa sublinhar que há uma relação triangular construída a partir do olhar entre o historiador do vídeo, suas fontes e seu público. O profissional da história define-se como mediador entre os que fizeram a história, legaram seus registros, estão querendo contá-la e aqueles que estão querendo ouvi-la e vê-la.

Por sua vez, o debate em torno da problemática do uso de entrevistas na produção dos documentários em cinema e vídeo revela a necessidade de se considerar a dimensão ética das produções culturais contemporâneas. O cineasta brasileiro, Eduardo Coutinho, em seu longa-metragem documental, Edifício Master, expôs o registro na tela do pagamento que realizava aos seus entrevistados pelo depoimento prestado. $\mathrm{O}$ argumento de defesa valoriza o tempo que os entrevistados concederam ao documentarista; outros, porém, condenaram o cineasta pelo ato de estetizar a pobreza, às custas de um baixo cachê. A polêmica se estende mundo afora, levantando questões que vão do excessivo valor atribuído à estética da fome, pelos documentaristas do Terceiro Mundo, à contrapartida autoral de certos entrevistados, como no caso do processo judicial contra o cineasta francês Nicolas Philibert, processado pelo personagem central de seu documentário Ser e Ter, que reclama co-autoria.

No entanto, o que há de se valorizar é o acordo estabelecido entre as partes no momento de organização do projeto. Quanto maior o envolvimento entre os integrantes do projeto, quanto maior a perspectiva de colaboração, quanto mais a autoridade autoral for compartilhada, tanto mais autêntico será o resultado documental. Não se trata de ver no tratamento do documentário uma verdade absoluta inscrita em dados objetivos, mas de encarar o fato documental como expressão de uma verdade relativa à dinâmica narrativa da história e aos processos de atualização das memórias sociais. 


\section{Cruzando narrativas e textos}

Em geral, ao buscar re-compor as camadas de significado sobre um determinado acontecimento, o historiador deve lidar com as várias narrativas do mesmo fato, numa só história. No caso do incêndio do Gran Circus Norte-Americano, as narrativas de época se apresentaram em várias mídias, abarcando jornal, revista e fotografia, e também podem ser vistas nos documentos oficiais e nos testemunhos das lembranças de quem viveu a época.

Nos jornais podemos perceber uma narrativa que resultou de um tratamento muito sintético e explicativo do desenrolar dos acontecimentos, a ponto de que qualquer leitor das reportagens sobre o incêndio pudesse entender de forma objetiva e clara o que ocorria. Pesquisada em vários periódicos de importância na época como o Correio da Manhã, Jornal do Brasil, e O Fluminense, a narrativa jornalística apresenta-se como uma síntese do fato, que se alonga até o primeiro terço de 1962. As matérias de jornal foram produzidas de modo que poderiam ser de um redator que sequer esteve no local dos acontecimentos, com a preocupação principal de estabelecer um tratamento o mais objetivo e sintético possível.

As revistas pesquisadas, ao contrário dos jornais, constroem o episódio de forma a valorizar mais as imagens do que os fatos propriamente ditos. A narrativa construída e transmitida ao público nada mais é do que uma forma de passar o clima dos acontecimentos por meio das fotos e de pequenos textos verbais não aprofundados sobre o tema tratado nas fotos, individualmente, ou em conjunto. Essa desvalorização do texto escrito a favor da imagem leva a uma certa falta de embasamento, já que não há um tratamento mais evidenciado da palavra que forneça elementos não visuais ao desenrolar dos acontecimentos. As fotos, apesar de expressivas, não falam totalmente por si só. Vê-se uma diferença muito grande entre as fotos localizadas nos jornais e as fotos das revistas. Estas últimas apresentam um caráter muito mais sensacionalista ao apresentar imagens de corpos queimados e o desespero explícito dos parentes, enquanto as fotos dos jornais são mais leves, limpas e calcadas no sinistro policial, nas autoridades governamentais e na solidariedade da população.

Seguindo essa pluralidade de abordagens, temos ainda os testemunhos de pessoas que estiveram envolvidas diretamente nos acontecimentos do incêndio do circo e que deixaram suas lembranças em entrevistas 
gravadas. Ao recordarem e contarem a experiência vivida no passado pessoal, os entrevistados apresentam outra visão do fato, desta vez incondicionalmente subjetiva. É certo de que cada entrevistado revela uma perspectiva própria sobre o incêndio, uma vez que o fato foi vivenciado de maneira diferente. Os depoimentos foram divididos de acordo com a atuação e a situação do entrevistado no incêndio do circo. Há as vítimas diretas, os familiares das vitimas, os médicos e testemunhas envolvidas ou não no trato e resgate dos feridos.

A narrativa que pode ser tirada das vítimas é centrada na dor, sofrimento e na recuperação. Falam sobre o circo em geral, e de como estava cheio - já que era uma das poucas opções de entretenimento na cidade; relatam como foram angustiantes e desesperadores a correria e o sufocamento causados pela multidão e pela caída da lona; sobre como tiveram forças para agüentar uma recuperação dolorosa e interminável. É importante ressaltar que nem todas as vítimas estavam dispostas a comentar sobre o incêndio, e gostariam que isso ficasse bem enterrado na memória delas. Mas há aqueles que, passando por um certo processo de catarse, fizeram questão de relatar, nos mínimos detalhes, tanto seu sofrimento como sua alegria perante a esperança de vida. Encontram-se, assim, duas narrativas realizadas pelo mesmo grupo de entrevistados.

Já os familiares das vítimas tratam da trajetória do parente falecido, desde a ida ao circo até a confirmação de sua perda. A construção narrativa é feita com muito pesar, pois a lembrança do trauma causada pelas mortes é ainda clara. O luto é evidenciado e seguido pelo relato do dia seguinte.

Os médicos possuem uma construção narrativa diretamente ligada ao âmbito da recuperação e tratamento imediato das vítimas. Fazem um relato às vezes mais técnico e previamente construído do que propriamente subjetivo. Relatam os casos mais graves e as próprias condições do Hospital das Clínicas (hoje Antônio Pedro), visto que de qualquer forma o incêndio foi um grande choque devido ao número de mortos e feridos.

Para os envolvidos no resgate e no apoio às vítimas, vemos que estes, a todo momento relatam a situação horrível dos feridos e como o processo de recuperação fisico-mental se desenvolveu. Não estão, a princípio, preocupados em comentar as causas, os culpados e, sim, recriar o momento imediato do fato e toda a rede de solidariedade proporcionada pelos voluntários que se sentiam na obrigação de ajudar o próximo. 
Diante de tantas narrativas presentes nesse único fato, o vídeo surge como alternativa de congregar e apresentar esse emaranhado, fazendo com que os recursos utilizados sejam transformados em uma única narrativa capaz de fundir todas as alternativas de narração. Assim há a possibilidade de se aproveitar todo esse material audiovisual que foi recolhido durante a disciplina de História Oral desenvolvida, pois era, aos nossos olhos, fundamental utilizar essa base de informações sobre o incêndio do circo.

\section{Escrita videográfica e análise histórica}

Nós, historiadores, infelizmente ainda estamos muito presos à forma escrita da expressão historiográfica. No processo da pesquisa desenvolvida, o vídeo surgiu como uma necessidade de expressar a riqueza das formas narrativas que envolveram a atualização da memória sobre o acontecimento. Paralelamente apresentou-se como a expressão mais adequada para cruzar textos e imagens, e, ainda, retornar aos entrevistados um produto do seu trabalho de rememoração.

A primeira estratégia para organização do roteiro do vídeo foi cruzar a narrativa oral produzida pelos depoentes com a narrativa visual produzida pela fotografia. Sendo assim, trabalhamos com o roteiro das entrevistas como fio condutor do re-arranjo das imagens veiculadas pela imprensa, base da composição visual, estabelecendo o limite de 10 minutos para a duração do vídeo. O resultado preliminar foi o seguinte: $1^{\circ}$ bloco: o dia do espetáculo, com cenas sobre Niterói para contextualizar o acontecimento espacialmente; $2^{\circ}$ bloco: a tragédia e os desdobramentos imediatos - atendimento das vítimas, enterro dos corpos; $3^{\circ}$ bloco: os culpados e a presença das autoridades governamentais; $4^{\circ}$ bloco: o dia seguinte e as repercussões do acontecimento; $5^{\circ}$ bloco: memória e esquecimento - onde foi o circo e o que lá existe hoje; $6^{\circ} \mathrm{bloco}$ : escrevendo por meio de imagens - o grupo.

Para cada um dos blocos distribuímos fotos, que foram filmadas por Tarsila Pimentel com uma câmera digital Sony. Tarsila, graduanda do curso de cinema, teve uma atuação fundamental para estabelecer a interface entre o que o historiador quer dizer sobre o acontecimento e como este objetivo pode ser expresso por meio da linguagem fílmica. 
Paralelamente, definimos que não haveria voz de narração em off e que os próprios entrevistados estabeleceriam a base narrativa do vídeo. Tal escolha obrigou-nos a fazer uma edição dos depoimentos com base no roteiro. Logo na primeira avaliação escolhemos os depoimentos dos sobreviventes, de um parente de sobrevivente, do médico e da escoteira como a base para a composição do áudio do vídeo. Recolhemos partes transcritas dos depoimentos e fomos compondo um texto corrido, mosaico de múltiplas falas. Feito isso, identificamos o tempo e o espaço da gravação original em que constava o registro da fala escolhida, e depois o trecho foi recortado e recomposto na fita final do áudio. Para garantir uma melhor qualidade técnica, as fitas foram digitalizadas e receberam um tratamento para melhorar o áudio.

Decidimos também que os blocos temáticos seriam antecedidos por intertítulos para facilitar a compreensão do argumento. $\mathrm{O}$ fundamental era ressaltar o objetivo principal, que era apresentar a composição polifônica do texto histórico. As imagens e vozes falavam da mesma coisa, mas de modos distintos. Desse modo, reconhecemos também que não há como se chegar ao que "realmente aconteceu", uma vez que a ilusão cientificista foi há muito ultrapassada no pensamento histórico. Assim, o mais importante era recompor os quadros da memória social através do qual o acontecimento é atualizado e os mecanismos que o historiador dispõe para lidar com a base intersubjetiva de medição com o passado.

Outra intervenção importante de ser destacada foi a inclusão de cenas sobre lazer em Niterói para contextualizar o lugar ocupado pelo circo, dentre os espaços de sociabilidade da época. Tais cenas foram compostas com fotos encontradas no arquivo da Fundação de Arte de Niterói e cedidas para filmagem. Dessa forma, a abertura da narrativa se processa do geral, fechando o foco no acontecimento, varrendo seus significados com um olhar detalhado através do jogo de ângulos e aproximações da câmera.

As fotografias foram filmadas buscando-se recuperar o movimento latente do olhar sobre a imagem fixa. A linguagem fotográfica condensa no olhar tempo e espaço, através da composição visual dos elementos no quadro. Quando a câmera de vídeo filma a fotografia, escolhendo ângulos, movendo-se pela superfície da foto, aproximando ou afastando o foco, recortando detalhes, ela refaz a sintaxe fotográfica inscrevendo o tempo do movimento do olhar. O elemento diferenciador entre a filmagem de cenas em movimento e de cenas fixas reside, justamente, na inscrição 
de um novo sujeito que olha uma imagem já vista, redimensionado o seu significado na composição da narrativa visual. A repetição de imagens garantiu tal princípio na medida em que, ao se evitar a super afluência visual, a cada nova cena a mesma imagem surgia ressematizada. Visando obter tal resultado, tivemos cuidado em sintonizar o modo de filmar e enfocar elementos visuais com o que se estava dizendo. A integração de sentido foi definida pela tensão entre ver e escutar.

Além de querer explicar as dimensões do trauma na história social e caracterizar as estratégias de esquecimento e rememoração utilizadas por uma comunidade de sentido (os que viveram a tragédia do circo de forma próxima), o projeto também teve como objetivo inscrever a memória do acontecimento na memória da cidade. Tal necessidade levou-se a visitar os espaços da cidade e identificar o lugar em que o circo foi montado e incendiado - hoje a policlínica do exército. Filmamos, neste local, a ausência de referências, expondo a construção do silenciamento.

Finalmente, sentimos necessidade de indicar que as memórias não são espontâneas - antes de tudo, resultam de um esforço coletivo de não deixar que vivências significativas caiam no esquecimento, ou fiquem reclusas nos porões da memória. Nesse sentido, era importante evidenciar quem eram os sujeitos que estavam por detrás da câmera, ou do gravador, incentivando a lembrança e incitando a memória, com o objetivo produzir um conhecimento por meio do cruzamento de palavras e imagens num texto de significado histórico. Concluímos a filmagem com uma cena do grupo trabalhando.

\section{Conclusão}

Ao mesmo tempo em que ficou clara a inexistência de um lugar de memória para o acontecimento, por meio de marcos de natureza material, percebeu-se a latência do fato na memória social da cidade. Portanto, todo o trabalho de atualização da memória do grupo de entrevistados realizou também o sentido de criar um lugar de memória para o vivido, em que o vídeo seria o melhor monumento. Um produto que pode ser devolvido aos depoentes como o resultado do seu esforço de lembrar, marcado pelo sofrimento da perda, da mutilação e da ausência, mas também pela plenitude da vida. 
O projeto sobre o incêndio do circo de 1961, em Niterói, não se esgotou com o término do curso instrumental de História Oral, mas desdobrou-se em diferentes produtos, dentre eles este vídeo. Tais resultados compartilharam o mesmo objetivo: relacionar a memória da cidade à memória da tragédia como dimensões de uma mesma experiência social.

Desta experiência de pesquisa no nível de graduação - com uma temática e metodologia relacionada à história oral e agregando a discussão sobre a linguagem visual e o uso do vídeo na escrita da história - podemos destacar a contribuição que este tipo de criação aporta para a formação renovada do profissional de história. No seu desenvolvimento, a experiência de integração de teoria e prática de pesquisa histórica coloca questões sobre a natureza epistemológica da produção do conhecimento histórico, de modo atualizado com as tendências da historiografia atual. A história ganha matéria, rosto e voz, os acontecimentos são trabalhados na sua projeção de lembrança, obrigando à problematização das noções de temporalidade e escala. Cremos que o exercício renovado do ofício do historiador parece ter sido a grande conquista deste trabalho em equipe.

\section{Referências bibliográficas}

FERRO, Marc. O filme: uma contra-análise da sociedade? In: NORA, Pierre; LE GOFF, Jacques. História: Novos Objetos. Rio de Janeiro: Francisco Alves, 1982.

MRAZ, John. Vídeo e historia. Revista de Historia Oral. México, 1999.

NORA, Pierre. O Retorno do Fato, In: História, Novos Problemas. São Paulo: Francisco Alves, 1976.

ROUSSO, Henry. Le Syndrome de Vichy de 1944 à nos jours. Paris: Seuil, 1990. (Coll. PointsHistoire).

SAMARAN, Charles (dir.). L’bistoire et ses méthodes. Paris, Gallimrd, 1961. (Encyclopédie de la Pléiade).

Resumo: $\mathrm{O}$ artigo apresenta o desenvolvimento de uma escrita histórica feita de palavras e imagens, identificada como a experiência videográfica do LABHOI/ UFF. Tomando como referência uma pesquisa em história oral sobre um acontecimento, o incêndio do Gran Circus Norte-Americano (Niterói,1961), o artigo tem como objetivo descrever todo o processo de investigação, incluindo-se a organização do grupo de estudantes engajados na pesquisa, a definição do assunto, da comunidade de entrevistados e o resultado final - um vídeo de 20 minutos. 
Destaca também questões éticas associadas ao uso de vozes e imagens em produções culturais e a efetividade deste tipo de narrativa no trabalho em história.

Palavras-chave: memória videográfica; história oral; investigação histórica.

\section{Memory in movement: the LABHOI/UFF videographic's experience}

Abstract: The article presents the development of an historical writing made by words and images, identified as the videographic experience of the Laboratory of Oral History and Image/UFF. Based upon an oral history research of an event, the fire of the Gran Circus Norte-Americano (Niterói,1961), the article aims to describe the whole process of the investigation, including the organization of the group of the students engaged on the research, the definition of the subject, the community of interviewees and the final result - a twenty minutes video. It also addresses ethical issues in using the voices and the images in a cultural production and the effectiveness of this kind of narrative in historical work.

Keywords: videographic memories; oral history; historical investigation. 